\title{
Impact of treatment planning and delivery factors on gastrointestinal toxicity: an analysis of data from the RADAR prostate radiotherapy trial
}

Noorazrul Yahya ${ }^{1,2^{*}}$, Martin A Ebert ${ }^{1,3}$, Max Bulsara ${ }^{4}$, Annette Haworth ${ }^{5,6}$, Rachel Kearvell ${ }^{3}$, Kerwyn Foo ${ }^{7}$, Angel Kennedy ${ }^{3}$, Sharon Richardson ${ }^{3}$, Michele Krawiec ${ }^{3}$, David J Joseph ${ }^{3,8}$ and Jim W Denham ${ }^{9}$

\begin{abstract}
Background: To assess the impact of incremental modifications of treatment planning and delivery technique, as well as patient anatomical factors, on late gastrointestinal toxicity using data from the TROG 03.04 RADAR prostate radiotherapy trial.

Methods: The RADAR trial accrued 813 external beam radiotherapy participants during 2003-2008 from 23 centres. Following review and archive to a query-able database, digital treatment plans and data describing treatment technique for 754 patients were available for analysis. Treatment demographics, together with anatomical features, were assessed using uni- and multivariate regression models against late gastrointestinal toxicity at 18-, 36- and 54-month follow-up. Regression analyses were reviewed in the context of dose-volume data for the rectum and anal canal.

Results: A multivariate analysis at 36-month follow-up shows that patients planned using a more rigorous dose calculation algorithm (DCA) was associated with a lower risk of stool frequency (OR: 0.435, Cl: 0.242-0.783, corrected $p=0.04)$. Patients using laxative as a method of bowel preparation had higher risk of having increased stool frequency compared to patients with no dietary intervention (OR: 3.639, Cl: 1.502-8.818, corrected $p=0.04$ ). Despite higher risks of toxicities, the anorectum, anal canal and rectum dose-volume histograms (DVH) indicate patients using laxative had unremarkably different planned dose distributions. Patients planned with a more rigorous DCA had lower median DVH values between $\mathrm{EQD} 2_{3}=15 \mathrm{~Gy}$ and $\mathrm{EQD} 2_{3}=35 \mathrm{~Gy}$. Planning target volume (PTV), conformity index, rectal width and prescription dose were not significant when adjusted for false discovery rate. Number of beams, beam energy, treatment beam definition, positioning orientation, rectum-PTV separation, rectal length and mean cross sectional area did not affect the risk of toxicities.

Conclusions: The RADAR study dataset has allowed an assessment of technical modifications on gastrointestinal toxicity. A number of interesting associations were subsequently found and some factors, previously hypothesised to influence toxicity, did not demonstrate any significant impact. We recommend trial registries be encouraged to record technical modifications introduced during the trial in order for more powerful evidence to be gathered regarding the impact of the interventions.
\end{abstract}

Keywords: Gastrointestinal toxicity, Prostate cancer, Technical modifications, Dose-volume histogram

\footnotetext{
* Correspondence: noorazrul.yahya@research.uwa.edu.au

${ }^{1}$ School of Physics, University of Western Australia, Crawley, Western

Australia, Australia

${ }^{2}$ School of Health Sciences, National University of Malaysia, Bangi, Malaysia

Full list of author information is available at the end of the article
} 


\section{Introduction}

Technical modifications in radiotherapy are often incremental, introduced into practice in institutions as evidence emerges and technological capability materializes. Planning studies are used widely to quantify the superiority of the modifications on the basis of planned dose distributions [1]. Such studies assume a relationship between dose precision and what is considered a 'better' dose distribution and the actual impact the modifications have on patients.

For example, more rigorous dose calculation algorithms (DCA) are introduced because of their ability to correct for tissue heterogeneity [2] while more sophisticated beam modification devices allow for increased dose conformality around the target volume, resulting in a lower dose to surrounding healthy tissue. Although these treatment modifications are introduced into clinical practice after careful consideration of their dosimetric consequences, ambiguity can persist regarding their clinically relevant consequences.

Due to the incremental and uncritical nature of technical changes, their clinical impacts are only occasionally assessed by way of hypothesis via randomised clinical study of the factors themselves [3-5]. More frequently, treatment-related morbidities have been examined via theoretical analysis using data collected during a study for which such factors comprise covariates [6-9]. These studies were either single institutional $[3,4,6,7]$ or accruing from a small number of institutions [8]. Few, if any, have reported the benefits of these incremental advances in technique in the multicentre, randomised clinical trial setting.

Randomised controlled trials are typically not powered to determine the effect of these technical modifications on toxicity. Secondary analysis does however offer an alternative way to acquire evidence of probable clinical consequences [10], taking full advantage of the availability of such data to understand how treatment decisions affect outcomes [11]. Long follow-up time associated with randomised clinical trials may be able to close the clinical evidence gap introduced by incremental evolution in radiotherapy, known to be rather rapid. Furthermore, through collaborative efforts, meta-analyses of similar high quality clinical trial data has the potential to provide additional evidence to support the gain in clinical efficacy with the introduction of new technology.

The TROG 03.04 trial of Randomised Androgen Deprivation and RT (RADAR - NCT00193856) principally examined the impact of duration of androgen suppression (AS) therapy on intermediate and high-risk prostate cancer patients [12,13]. All patients had adjuvant RT and, as part of an extensive technical quality assurance (QA) program [14-16], considerable data was collected on treatment technique. With maturity of late toxicity information, these data have now been explored for any significant relationships between treatment planning and delivery factors and resulting gastrointestinal (GI) toxicity.

\section{Methods and materials Data collection}

The RADAR trial examined the influence of duration of AS with or without bisphosphonate treatment, adjuvant with radiotherapy. Data collection, protocol requirements and QA have been summarised previously [13,15-17]. This trial commenced accrual at a time when many participating centres were implementing conformal threedimensional (3D) treatment technologies and was consequently undertaken under detailed scrutiny of patient safety and treatment quality.

Of 1071 men accrued to the trial from 23 participating centres across Australia and New Zealand between 2003 and 2008, 813 had external beam radiotherapy (without a brachytherapy boost) and, of these, 754 had complete technical data available for the analysis presented here, comprising:

- Digital treatment plan export consisting of axial computed tomography (CT) slices at maximum $5 \mathrm{~mm}$ spacing; delineated clinical target volume (CTV - the prostate for intermediate-risk patients, and prostate with proximal seminal-vesicles for high-risk), planning target volume (PTV) for phase 1 treatment to 46 Gy (PTV1 - CTV $+1.0-1.5 \mathrm{~cm}$ margin, $0.5-1.0 \mathrm{~cm}$ posterior margin) and phase 2 boost (PTV2 - CTV $+0.0-1.0 \mathrm{~cm}$ margin, $<0.5 \mathrm{~cm}$ posterior margin) to 66,70 or 74 Gy; delineated outer rectal wall; 3D dose matrix for each phase; information on number of beams, beam energies and collimation method; utilised dose DCA; conformity index (CI) [18]

- Form-based information on patient, centre and treatment demographics, setup technique and dietary interventions.

Factors could be directly extracted, or derived, from the resulting archived data sets using the plan review software, 'SWAN' (Sir Charles Gairdner Hospital, Nedlands, WA, Australia) [19]. Several of these require a brief definition or description.

- Dose calculation algorithm: these have been categorised as either 'type- $a$ ' or 'type- $b$ ' according to the definitions of Fogliata et al. [2]. Briefly, type- $a$ algorithms do not account for changes in lateral electron transport due to inhomogeneity whereas type- $b$ algorithms do account of such changes. 
- Treatment beam definition: categorised as either 'MLC' (if defined by multileaf collimator), 'collimator' (if defined by secondary photon jaws only) or 'blocks' (if patient-specific custom-formed blocks were used).

- Setup orientation: refers to the orientation (prone or supine) of the patient at the time of planning CT scan, consistent with that at treatment.

- Rectal dietary intervention: refers to the intervention in each centre prior to planning CT and each treatment fraction, broadly categorised as 'no intervention,' 'laxative prior to planning CT and at least first week of treatment' and 'bulking agent with or without dietary instructions'. In all groups, patients were required to empty their rectum before planning and treatment.

- PTV-rectum separation: the distance between the anterior extent of the outer rectal wall and the PTV at the axial level of the centre-of-mass of the PTV (which may be negative if the two definitions intersect at that level).

- 95\% isodoses volume: volume, in $\mathrm{cm}^{3}$, of the $95 \%$ isodose for combined physical phase 1 and 2 isodoses.

- Conformity index (CI): Volume enclosed by $95 \%$ isodose surface/PTV [18].

- Rectal distension: the normal distance between the most anterior and most posterior coronal planes of the rectum containing points of the outer rectal wall at the level of the centre-of-mass of the gross tumour volume.

- Mean rectal cross-sectional area (CSA): obtained by dividing the total delineated rectum volume by the number of CT slices defining the cranio-caudal length of the rectum (see [20])

\section{Toxicity assessment}

After treatment, all patients were routinely followed up in clinic every 3 months for the first 18 months, then every 6 months up to 5 years post randomisation and then annually for a further 5 years. GI toxicities were assessed using two standard toxicity measurement apparatus; Common Toxicity Criteria v2.0 [21] for proctitis, and LENT-SOMA [22] for stool frequency, tenesmus, and rectal bleeding. Due to the low number of patients reporting high level toxicity, the grade cut-point was adjusted to include patients reporting low level toxicity as shown on Table 1. Patients with pre-treatment symptoms were excluded for that particular endpoint. As the cumulative incidence analysis may overestimate the actual toxicity burden and may have higher level of noise [23,24], the prevalence was used in the current analysis. The toxicity prevalence at 18, 36 and 54 months after randomisation were presumed to be representative of the late toxicity.
Table $1 \mathrm{Gl}$ endpoints, the scoring system, baseline criteria for exclusion and the prevalence at 18-, 36- and 54-month follow-up

\begin{tabular}{lllll}
\hline $\begin{array}{l}\text { Scoring system } \\
\text { selected } \\
\text { endpoint }\end{array}$ & $\begin{array}{l}\text { Baseline } \\
\text { criteria \& grade } \\
\text { cut-point }\end{array}$ & \multicolumn{3}{l}{ Prevalence at } \\
\cline { 5 - 6 } & 18-month & 36-month & 54-month \\
\hline CTC v2.0 [21] & $>0$ & $134 / 713$ & $116 / 639$ & $83 / 482$ \\
Proctitis & $>0$ & & & \\
LENT-SOMA [22] & & $264 / 716$ & $220 / 639$ & $168 / 487$ \\
Stool frequency & $>0$ & $198 / 716$ & $174 / 638$ & $116 / 487$ \\
Tenesmus & $>0$ & $134 / 716$ & $140 / 639$ & $114 / 487$ \\
\hline Rectal bleeding & $>0$ & &
\end{tabular}

CTC v2.0, Common Toxicity Criteria (version 2); LENT-SOMA, Late Effects of Normal Tissues-Subjective, Objective, Management, Analytic.

For the rest of this paper, proctitis $(\mathrm{P})$ at 18-, 36- and 54-month follow-up will abbreviated as P-18, P-36 and $\mathrm{P}-54$ respectively. Similar convention is used for stool frequency (SF), tenesmus ( $\mathrm{T}$ ), and rectal bleeding (RB).

\section{Statistical analysis}

The impact of treatment planning and delivery factors on the occurrence of GI toxicity was analysed by uni- and multivariate analysis. Univariate analysis was performed for endpoints to determine odds-ratio (OR). Unselected multivariate logistic regression analysis (with all factors included regardless of statistical significance in univariate analysis) was used to look for the relative contributions of the factors. Adjustments for potential confounders were made for age, risk category, body mass index (BMI) and the year of treatment. Because many variables were included in the analysis, the Benjamini \& Hochberg false discovery rate (FDR) adjustment for multiple testing was performed [25] which is less conservative than the Bonferroni method. Specifically, we apply the Benjamini \& Hochberg adjustment in $\mathrm{R}$ to map each $p$-value to a FDR-corrected $p$-value, which can be interpreted as the probability that the given factor is a false discovery [26]. FDR-adjusted $p$-values $<0.05$ were considered statistically significant.

\section{DVH analysis}

Each patient's anorectum was delineated prior to data submission and archive, and manually reviewed and redefined by SR and MK according to the 'anorectum' definition from Peeters et al. (defined as outer rectal wall from the level of the ischial tuberosities until when the rectum turns horizontally to the sigmoid colon) from which the inferior $3 \mathrm{~cm}$ were defined separately as the 'anal canal' and the remaining as the 'rectum' [27]. Doses for individual treatment phases were combined as equivalent dose in EQD2 ${ }_{3}=2$ Gy [28], and an independent calculation undertaken in SWAN [19] of the anorectum 
relative cumulative dose-volume histogram (DVH). Dose/ volume threshold indices (labelled as V1, V2 ...) represent the relative proportions of anorectum/anal canal/rectum volume receiving more than a given dose in 1 Gy intervals. Median anorectum/anal canal/rectum DVH curves were derived for patient groups defined according to the significant variable categories or a dichotomisation of continuous variables about their median. The $95 \%$ confidence interval of the respective median volume at each EQD2 3 point was derived from $10^{4}$ bootstrap samples. These DVH curves are not intended to be studied as one of the variables but rather to detect whether there are differences in dose distribution as a result of different treatment planning and delivery factors used. Comprehensive DVH analysis has been published elsewhere [29].

\section{Results}

\section{Data and toxicity description}

Distributions of investigated parameters are shown in Table 2. CI (phase 2), 95\% isodose volume, and rectal volume were excluded from analysis because of the strong

Table 2 Distributions of investigated factors

\begin{tabular}{|c|c|}
\hline Participants & \\
\hline Age & $69 \pm 7(49-85)$ years \\
\hline BMl & $27.98 \pm 4.12(17.17-45.77) \mathrm{kg} / \mathrm{m}^{2}$ \\
\hline Year commenced EBRT & $\begin{array}{l}\text { 2004(125); 2005(200); 2006(234); 2007(181); } \\
\text { 2008(12) }\end{array}$ \\
\hline Risk category & Intermediate (464); High (290) \\
\hline \multicolumn{2}{|l|}{$\begin{array}{l}\text { Planning \& Delivery } \\
\text { factors }\end{array}$} \\
\hline Dose calculation algorithm [2] & Type- $a$ (401); Type- $b$ (350) \\
\hline Patient orientation at set-up & Prone (66); Supine (687) \\
\hline Prescription dose & 66Gy (99); 70Gy (423); 74Gy (229) \\
\hline Treatment beam definition & Block/collimator (259); MLC (484) \\
\hline Beam energy & $6 \mathrm{MV}(96) ; 10 \mathrm{MV}(158) ; 15 \mathrm{MV}(5) ; 18 \mathrm{MV}$ (493) \\
\hline Number of beams & 3 (89); 4 (396); 5 (155); 6 (110);7 (2) \\
\hline Rectal dietary intervention & $\begin{array}{l}\text { No intervention (280); laxatives (77); } \\
\text { bulking agent (394) }\end{array}$ \\
\hline \multicolumn{2}{|l|}{$\begin{array}{l}\text { Anatomical/Dosimetric } \\
\text { parameters }\end{array}$} \\
\hline PTV1 volume & $192 \pm 65(30-704) \mathrm{cm}^{3}$ \\
\hline $95 \%$ isodose volume & $257 \pm 104(60-1425) \mathrm{cm}^{3}$ \\
\hline Conformity index [18] & $1.34 \pm 0.26(0.72-2.94)$ \\
\hline Rectal cranio-caudal length & $9.6 \pm 1.3(5.4-13.5) \mathrm{cm}$ \\
\hline Mean rectal CSA & $7.9 \pm 3.4(0.1-26.7) \mathrm{cm}^{2}$ \\
\hline PTV-rectum separation & $0.12 \pm 0.32(-2.6-3.39) \mathrm{cm}$ \\
\hline
\end{tabular}

Continuous factors are specified as mean \pm standard deviation (range), categorical factors are specified as category (number of patients). Not all patients available for all assessments due to missing data, exclusions etc. Abbreviations: BMI Body mass index, EBRT External beam radiotherapy, PTV1 Phase 1 planning target volume (PTV), CSA Cross sectional area. correlation (Spearman R $>0.8$ ) to CI (phase 1), PTV and mean rectal CSA respectively. Table 2 shows the distribution of patients with and without toxicities for each endpoints at timepoints.

\section{Outcomes analysis}

The results of univariate logistic analysis of treatment planning and delivery factors affecting late effects, with significant factors highlighted, are shown in Additional file 1. Some factors, including DCA, number of beams and beam energy found to be significantly associated with at least 3 endpoints but none of the factors remain significant after FDR adjustments. The multivariate results for significant factors are in Table 3. At 36-month followup post-randomisation, patients planned with type- $b$ DCA were associated with lower risk of having increased SF-36 (OR: 0.435, CI: 0.242-0.783, FDR-adjusted $p=0.04$ ). At 54-month, a similar association was found albeit weaker (unadjusted $p$-value $<0.10$ ). Similar trends towards significance were also found between the DCA and RB-36 and RB-54). Patients using laxatives as a pre-treatment rectal preparation had higher risk of SF-36 compared to patients with no rectal dietary intervention (OR: 3.639, CI: 1.5058.818, FDR-adjusted $p=0.04$ ). The effect of laxative as a pre-treatment rectal preparation was also found to show a trend toward significance for SF-18 and T-18. Planning target volume (PTV), conformity index, rectal width and prescription dose were not significant when adjusted for false discovery rate. However, special attention is given to PTV. Before adjustment for multiple comparisons [25], increasing PTV is significantly associated with increasing risk of SF at 18- and 54-month while at 36-month the association shows a suggestive trend $(p=0.06)$. Number of beams, beam energy, treatment beam definition, positioning orientation, rectum-PTV separation, rectal length and mean cross sectional area did not affect the risk of toxicities in multivariate analysis.

\section{DVH comparisons}

Median anorectum, anal canal and rectum DVH curves for all patients in the study according to the treatment factors of interests are shown on Figure 1 (i-ix). At lower doses, it was found that the difference of the median relative volume of the anorectum receiving between $\mathrm{EQD2} 2_{3}=$ 15 Gy and EQD2 $2_{3}=35$ Gy is significant between plans using type- $a$ and type- $b$ with maximum difference of $8 \%$ at V25; lower for type- $b$. However, at higher doses the differences were unremarkable. The same is also seen for anal canal and rectum DVHs. For dietary intervention, median DVHs were found to be unremarkably different for patients administered with pre-simulation treatment laxative compared to those with no dietary intervention or prepared with a bulking agent. Consistently higher median volumes were found for patients with PTV $\leq$ median 
Table 3 Multivariate analysis examining relationship between treatment factors to late gastrointestinal toxicities

\begin{tabular}{|c|c|c|c|c|c|c|c|c|c|c|c|c|}
\hline \multirow[b]{2}{*}{ Endpoint } & \multicolumn{4}{|l|}{18 months } & \multicolumn{4}{|l|}{36 months } & \multicolumn{4}{|l|}{54 months } \\
\hline & Variable & $\mathbf{P}$ & $\mathrm{P}^{*}$ & $\mathrm{OR}(\mathrm{Cl})$ & Variable & $\mathbf{P}$ & $\mathrm{P}^{*}$ & OR (Cl) & Variable & $\mathbf{P}$ & $\mathrm{P}^{*}$ & OR (Cl) \\
\hline \multirow[t]{2}{*}{ Proctitis } & $\begin{array}{l}\text { Orientation } \\
\text { (prone vs supine) }\end{array}$ & 0.051 & NS & $2.467(0.996-6.111)$ & $\begin{array}{l}\text { Conformity index } \\
\text { (continuous) }\end{array}$ & 0.032 & NS & $3.157(1.102-9.046)$ & & & & \\
\hline & Mean CSA $\left(\right.$ per $\left.\mathrm{cm}^{2}\right)$ & 0.062 & NS & $0.926(0.854-1.004)$ & & & & & & & & \\
\hline \multirow[t]{4}{*}{ Rectal bleeding } & & & & & $\begin{array}{l}\text { Dose calculation } \\
\text { algorithm } \\
\text { (type- } b \text { vs type-a) }\end{array}$ & 0.011 & NS & $0.479(0.271-0.847)$ & $\begin{array}{l}\text { Dose calculation } \\
\text { algorithm } \\
\text { (type- } b \text { vs type-a) }\end{array}$ & 0.055 & NS & $0.561(0.311-1.013)$ \\
\hline & & & & & $\begin{array}{l}\text { Rectal width } \\
(\text { per } \mathrm{cm})\end{array}$ & 0.026 & NS & $0.726(0.548-0.963)$ & & & & \\
\hline & & & & & $\begin{array}{l}\text { Prescription } \\
\text { dose (per Gy) }\end{array}$ & 0.021 & NS & $0.876(1.017-1.158)$ & & & & \\
\hline & & & & & PTV $\left(\right.$ per $\left.\mathrm{cm}^{3}\right)$ & 0.061 & NS & $1.003(1-1.007)$ & & & & \\
\hline \multirow[t]{4}{*}{ Stool frequency } & $\begin{array}{l}\text { Rectal intervention } \\
\text { (bulking agent vs } \\
\text { no intervention) }\end{array}$ & 0.049 & NS & $0.78(0.436-1.395)$ & $\begin{array}{l}\text { Dose calculation } \\
\text { algorithm } \\
\text { (type- } b \text { vs type-a) }\end{array}$ & 0.006 & 0.039 & $0.435(0.242-0.783)$ & $\begin{array}{l}\text { Dose calculation } \\
\text { algorithm } \\
\text { (type- } b \text { vs type-a) }\end{array}$ & 0.079 & NS & $0.554(0.287-1.07)$ \\
\hline & $\begin{array}{l}\text { Rectal intervention } \\
\text { (laxative vs no } \\
\text { intervention) }\end{array}$ & 0.053 & NS & $1.749(0.801-3.819)$ & $\begin{array}{l}\text { Rectal intervention } \\
\text { (laxative vs no } \\
\text { intervention) }\end{array}$ & 0.003 & 0.039 & 3.639 (1.502-8.818) & $\begin{array}{l}\text { Number of beam } \\
\text { (per } 1 \text { beam) }\end{array}$ & 0.083 & NS & $0.692(0.457-1.049)$ \\
\hline & PTV $\left(\right.$ per $\left.\mathrm{cm}^{3}\right)$ & 0.022 & NS & $1.004(1.001-1.007)$ & PTV $\left(\right.$ per $\left.\mathrm{cm}^{3}\right)$ & 0.059 & NS & $1.004(1-1.007)$ & PTV $\left(\right.$ per $\left.\mathrm{cm}^{3}\right)$ & 0.008 & NS & $1.007(1.002-1.012)$ \\
\hline & $\begin{array}{l}\text { PTV-rectal } \\
\text { separation (per cm) }\end{array}$ & 0.061 & NS & $1.84(0.971-3.486)$ & $\begin{array}{l}\text { Conformity index } \\
\text { (continuous) }\end{array}$ & 0.049 & NS & $0.293(0.087-0.993)$ & & & & \\
\hline \multirow[t]{2}{*}{ Tenesmus } & $\begin{array}{l}\text { Number of } \\
\text { beam (per } 1 \text { beam) }\end{array}$ & 0.085 & NS & $0.775(0.581-1.036)$ & & & & & & & & \\
\hline & $\begin{array}{l}\text { Rectal intervention } \\
\text { (laxative vs no intervention) }\end{array}$ & 0.072 & NS & $2.058(0.971-4.364)$ & & & & & & & & \\
\hline
\end{tabular}
(laxative vs no intervention)

Abbreviations: $P$ p-value, $P^{*}$ False-discovery-rate-adjusted $p$-value [25], OR (CI) odds ratio (95\% confidence interval), CSA Cross sectional area, $P T V$ Planning target volume, NS not significant. Only variables with uncorrected $p$-value $<0.10$ are shown. 

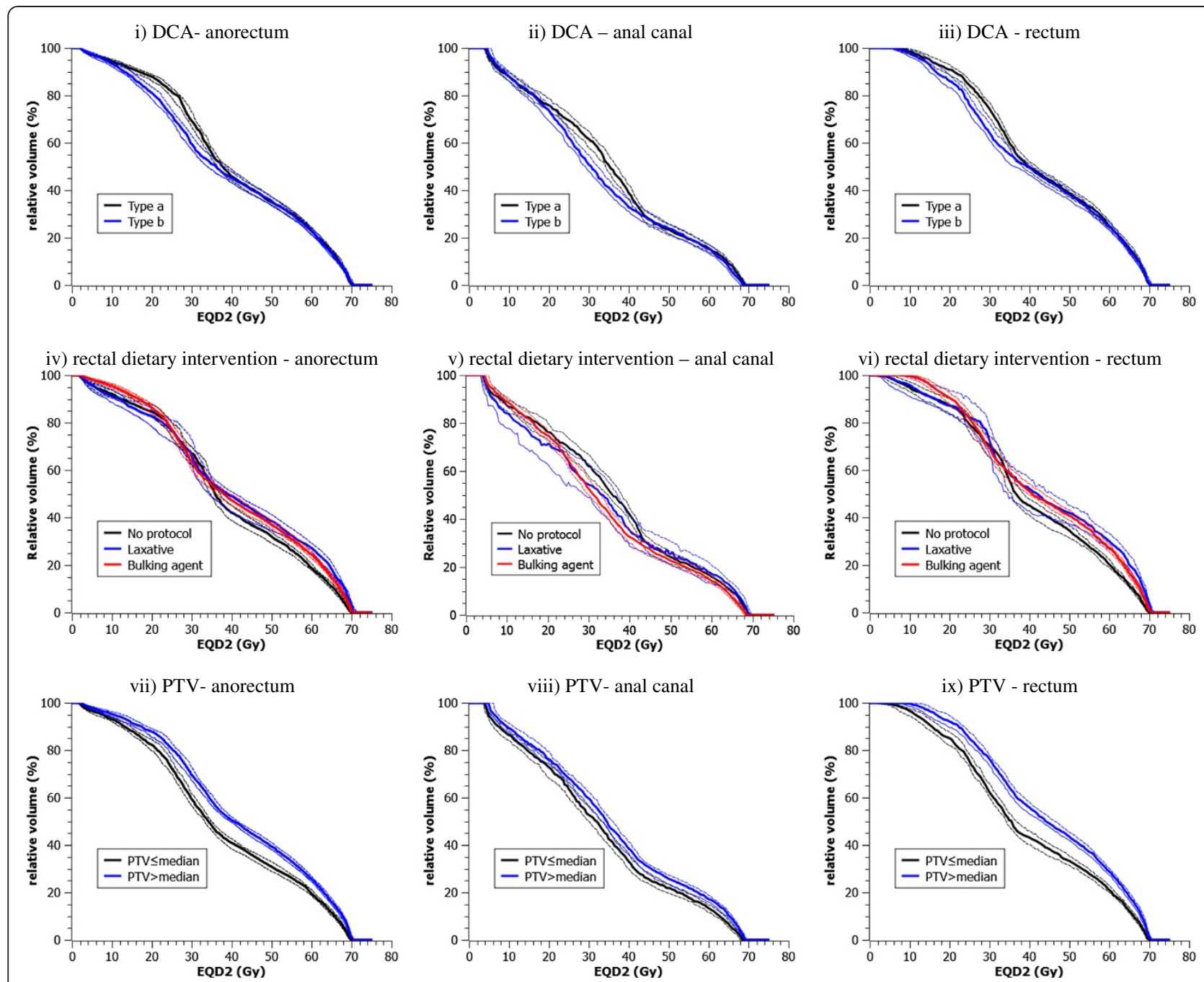

Figure 1 Median anorectum, anal canal and rectum dose volume histogram (DVH) curves according to the dose calculation algorithm (DCA), rectal dietary intervention and PTV. The dashed lines are the $95 \%$ confidence interval of the respective median derived from $10^{4}$ bootstrap samples.

compared to > median especially for anorectum and rectum DVHs.

\section{Discussion}

In the current study, we report on the treatment planning, delivery and anatomical factors impacting late GI toxicities following external beam RT of the prostate.

This study has several unique and interesting features including the large number of patients with full data collation and the diversity of treatment technique across 23 institutions. Data was prospectively collected in a clinical trial setting, monitored by strict quality control and auditing requirements [16]. As the study was performed in the era of transition to fully 3-dimensional conformal radiotherapy (3DCRT), some modifications (e.g. DCA and beam-shaping devices) were captured as centres transitioned into newer technology. This unique opportunity allows the variations to be captured in a single study enabling analysis on a variety of treatment factors in the multivariate analysis setting. Additionally, toxicity-specific late endpoints were analysed to allow a more comprehensive analysis. This is unlike many other reports which focus on a single specific GI toxicity (e.g. rectal bleeding [6,30]) or use non-atomised symptoms grades (e.g. Radiation Therapy Oncology Group [RTOG] scale $[3,4,31])$.

We found that in multivariate analysis, several factors were found to affect the toxicity outcome.

1. Higher odds of stool frequency was found for patients administered with laxative compared to patients with no rectal preparatory intervention at 36-month follow-up and potentially at 18-month. Patients administered with laxative had 
unremarkable difference of planned dose distribution compared to patients who did not receive any interventions indicating that the decreased toxicity risk did not originate from differences in the planned dose distribution.

There are potentially two ways to look at this observation. First, compared to patients with no rectal intervention, laxative use helps to minimize the systematic error due to rectum motion during pelvic radiotherapy $[32,33]$ but this finding is not repeated in a randomised study [5]. This careful and more thorough emptying of rectum by laxative may also spare the rectal tissue from the benefit of the blurring effect due to the day-to-day spatial variations. Second, the intervention may have drug-radiation synergistic effect to increase damage to the intestinal villi caused by radiotherapy. Lips et. al found a trend towards slightly more gastrointestinal toxicity in the laxative arm than in the placebo arm in a randomised study [5].

2. Association of type- $a$ DCA used in planning to increased risks of stool frequency may be related to the dose distribution difference between the two DCAs. The disagreements between type- $a$ and type- $b$ has been proposed to be insignificant in prostate radiotherapy treatment because tissues in the pelvic region are generally homogeneous [34]. However, a treatment planning study comparing the effect of algorithm on the normal tissue complication probability (NTCP) model illustrated that the difference was not insignificant, with the use of type- $b$ resulting in lower NTCP when the same monitor units were used [35].

3. We found that patients with smaller PTV had less risk of gastrointestinal toxicity. This is similar to previous observations $[9,30,31]$ and is potentially attributable to the more favourable dose distribution for patients with smaller PTV.

Several factors found to be significant in previous studies were not found to be significant in this study, including rectum CSA $[6,30]$ and rectal length [6] potentially because of the difference in endpoint definition used. Prevalence, rather than cumulative incidence, at three late time points were used in this study to better reflect the actual toxicity burden and to reduce noise $[23,24]$. From the multivariate analysis shown here, it was found that several factors showed low $p$-values ( $p<0.05$, uncorrected) at a specific time point but were not repeated at other time points raising the suspicion that it might be due to data fluctuation or random discovery rather than actual long term associations. The confidence to report the associations between dietary intervention and DCA to toxicity risks, however, was greater as these factors were also found to have trend towards significance in other time points. This suggests sustained long-term associations.

The RADAR trial provided a rich dataset in terms of the variety of patient treatment and irradiation techniques used, resulting in diverse combinations of treatment approaches and dose distributions. All treatments were however based on 3DCRT and it is important to consider how the results derived here may be translated to patient treatment with image-guided and intensity-modulated radiotherapy (IMRT), which are now commonplace. IMRT produces a more conformal dose distribution to 3DCRT, enabling higher doses to be prescribed in larger dose per fraction while maintaining or decreasing the associated toxicities [7]. Firstly, the rectal preparatory interventions discussed in this study are still widely used in a more contemporary treatment delivery including IMRT [36]. We have speculated that the elevated risk of toxicity related to the use of laxative may have an origin largely unrelated to dosimetry. It is thus expected that the result is applicable to treatments using IMRT. A comparable effect of using laxative was also reported in a randomised study with IMRT as a method of treatment delivery using 77 Gy and $2.2 \mathrm{~Gy} /$ fraction regimen [5]. Secondly, the use of many small beam elements in IMRT to create steep and conforming dose gradients may profit more from the use of a more rigorous DCA [37]. While DCA has not been previously reported to affect homogenous tissue such as found in the pelvis [34], conflicting NTCP results have been observed [35]. Finally, better dose sculpting associated with IMRT delivery may reduce the impact of the PTV on stool frequency compared to what is observed in this study. Stool frequency is more strongly associated with dose to the anal canal [29]. Due to the distance of the anal canal from the PTV, relevant doses could be reduced by employing a treatment technique with sharper dose falloff. This may in part be compensated by the use of higher dose prescriptions, often aimed at maintaining iso-effect in normal tissues. It is unknown what the potential impacts might be of hypofractionation, common in modern treatments, on the relationships found here. As the $\alpha / \beta$ estimate for rectal toxicity is likely higher than that for prostate cancers, leading to a constant or lower proportional rectal toxicity rate in hypofractionation [38], it can be speculated that a less significant relationship between the treatment factors considered here and toxicity might be observed.

As an alternative to undertaking a randomised controlled trial of a specific technical modification, this study has demonstrated the benefit of careful archival of treatment demographics to reveal the clinical impact of treatment modifications. Even when datasets from clinical trials are not originally powered to assess the effects of these incremental technical modifications, such assessment may offer 
some valuable clinical insights [10]. With technical modifications typically introduced into practice incrementally and uncritically, derivation of Level III randomised trial evidence for the impact of such modifications is unlikely [39]. Consequently, little or no evidence is available regarding the existence or size of clinical impact of some of the technological modifications studied here. In most cases, the modifications were introduced with the immediate aim of improving treatment quality on the basis of prior successful planning dosimetric studies [1].

The notion to supplement the evidence from dosimetric studies with secondary analysis of the data from clinical trials to determine the clinical consequence is not new. Clinical trials data is associated with rigorous scrutiny, consistent adherence to protocol, quality assurance procedures and potentially less noise compared to retrospective analysis of day-to-day clinical cases making it an appropriate dataset for that purpose $[10,16,39]$. For example, the evidence of the benefit of the transition from 3DCRT to IMRT and image-guided radiotherapy has been successfully complemented by secondary analyses of clinical trials $[7,8]$. With more trial registries being encouraged to record the technical modifications introduced, the influence of technical treatment planning and delivery factors that may be clinically relevant can be studied more confidently [39].

The insights obtained in this study are hypothesisgenerating and require independent validation. Specific limitations in our analysis should be highlighted. The factors are not independent of each other, with many factors grouping together due to the technique, experience and manufacturer-dominated profiles of participating centres. It should also be noted that the influencing factor of centre reporting bias cannot be excluded.

\section{Conclusion}

The RADAR study dataset has allowed an assessment of treatment and anatomical factors previously hypothesised to impact on treatment-related GI toxicity. A limited number of significant associations were subsequently found which cannot always be explained by the underlying planned dosimetry. The ability to undertake this analysis was facilitated by careful collection of treatment and demographic data during the undertaking of the trial. Consequently, trial registries should be encouraged to record the technical modifications introduced.

\section{Additional file}

Additional file 1: Univariate analysis examining relationship between treatment factors to late gastrointestinal toxicities at 18-, 36- and 54-month follow-up.

\section{Abbreviations}

RADAR: Randomised androgen deprivation and radiotherapy; DCA: Dose calculation algorithm; OR: Odds ratio; DVH: Dose-volume histogram; $\mathrm{EQD2}_{3}$ : Equivalent dose in $2 \mathrm{~Gy}$ per fraction using $\alpha / \beta=3$; PTV: Planning target volume; RT: Radiotherapy; Gl: Gastrointestinal; QA: Quality assurance; CT: Computed tomography; CTV: Clinical target volume; PTV1: Planning target volume in phase 1; PTV2: Planning target volume in phase 2; Cl: Conformity index; MLC: Multileaf collimator; CSA: Cross sectional area; FDR: False discovery rate; 3DCRT: 3-Dimensional conformal radiotherapy; RTOG: Radiation Therapy Oncology Group; NTCP: Normal tissue complication probability.

\section{Competing interests}

The TROG 03.04 trial was financially supported by grant funding from Australian and New Zealand government, non-government and institutional sources. Pharmaceutical use and trial logistic support was provided by Abbott Laboratories and Novartis Pharmaceuticals. No financial benefits were paid to trial investigators or listed authors.

\section{Authors' contributions}

NY and MAE have made substantial contributions to conception and design of analysis; NY, MAE, AH, RK, KF, AK, SR, MK and JWD have made substantial contributions to acquisition of data; NY, MAE, MB to analysis and interpretation of data. NY has been involved in drafting the manuscript. MAE, AH, JWD, MB and AK revised it critically for important intellectual content. JWD and DJJ conceived and participated in the design and coordination of the RADAR trial. All authors have given final approval of the version to be published.

\section{Acknowledgements}

We acknowledge funding from Cancer Australia and the Diagnostics and Technology Branch of the Australian Government Department of Health and Ageing (grant 501106), the National Health and Medical Research Council (grants 300705, 455521, 1006447), the Hunter Medical Research Institute, the Health Research Council (New Zealand), the University of Newcastle, the Calvary Mater Newcastle, Abbott Laboratories and Novartis Pharmaceuticals. We gratefully acknowledge the support of the Sir Charles Gairdner Hospital, the 'Elvis' study team, the contour audit team, participating RADAR centres, Chantelle Wilcox, Allison Steigler, the Trans-Tasman Radiation Oncology Group, Jean Ball, Cate Sproston, Sean Hall, Celia Gordon, Scott Chandler, Scott Williams, Mahesh Kumar, Sean Bydder, Rhonda Coleman, Ben Hooton, Elizabeth van der Wath.

\section{Author details}

${ }^{1}$ School of Physics, University of Western Australia, Crawley, Western Australia, Australia. ${ }^{2}$ School of Health Sciences, National University of Malaysia, Bangi, Malaysia. ${ }^{3}$ Department of Radiation Oncology, Sir Charles Gairdner Hospital, Nedlands, Western Australia, Australia. ${ }^{4}$ Institute for Health Research, University of Notre Dame, Fremantle, Western Australia, Australia. ${ }^{5}$ Department of Physical Sciences, Peter MacCallum Cancer Centre, Victoria, Australia. ${ }^{6}$ Sir Peter MacCallum Department of Oncology, University of Melbourne, Victoria, Australia. ${ }^{7}$ Sydney Medical School, University of Sydney, Sydney, New South Wales, Australia. ${ }^{8}$ School of Surgery, University of Western Australia, Crawley, Western Australia, Australia. ${ }^{9}$ School of Medicine and Public Health, University of Newcastle, Newcastle, New South Wales, Australia.

Received: 30 September 2014 Accepted: 1 December 2014 Published online: 13 December 2014

\section{References}

1. Roelofs E, Persoon L, Qamhiyeh S, Verhaegen F, De Ruysscher D, Scholz M, lancu G, Engelsman M, Rasch C, Zijp L, Meerleer GD, Coghe M, Langendijk J, Schilstra C, Pijls-Johannesma M, Lambin P: Design of and technical challenges involved in a framework for multicentric radiotherapy treatment planning studies. Radiother Oncol 2010, 97:567-571.

2. Antonella F, Eugenio V, Dirk A, Carsten B, Alessandro C, Tommy K, Giorgia N, Luca C: On the dosimetric behaviour of photon dose calculation algorithms in the presence of simple geometric heterogeneities: comparison with Monte Carlo calculations. Phys Med Biol 2007, 52:1363.

3. Koper PC, Jansen P, van Putten W, van Os M, Wijnmaalen AJ, Lebesque JV, Levendag PC: Gastro-intestinal and genito-urinary morbidity after 3D 
conformal radiotherapy of prostate cancer: observations of a randomized trial. Radiother Oncol 2004, 73:1-9.

4. Dearnaley DP, Khoo VS, Norman AR, Meyer L, Nahum A, Tait D, Yarnold J, Horwich A: Comparison of radiation side-effects of conformal and conventional radiotherapy in prostate cancer: a randomised trial. Lancet 1999, 353:267-272.

5. Lips IM, van Gils CH, Kotte AN, van Leerdam ME, Franken SP, van der Heide $U A$, van Vulpen M: A double-blind placebo-controlled randomized clinical trial with magnesium oxide to reduce intrafraction prostate motion for prostate cancer radiotherapy. Int I Radiat Oncol Biol Phys 2012 83:653-660.

6. Skwarchuk MW, Jackson A, Zelefsky MJ, Venkatraman ES, Cowen DM, Levegrün S, Burman CM, Fuks Z, Leibel SA, Ling CC: Late rectal toxicity after conformal radiotherapy of prostate cancer (I): multivariate analysis and dose-response. Int J Radiat Oncol Biol Phys 2000, 47:103-113.

7. Zelefsky MJ, Kollmeier M, Cox B, Fidaleo A, Sperling D, Pei X, Carver B, Coleman J, Lovelock M, Hunt M: Improved clinical outcomes with high-dose image guided radiotherapy compared with non-IGRT for the treatment of clinically localized prostate cancer. Int I Radiat Oncol Biol Phys 2012, 84:125-129.

8. Al-Mamgani A, Heemsbergen WD, Peeters ST, Lebesque JV: Role of intensity-modulated radiotherapy in reducing toxicity in dose escalation for localized prostate cancer. Int I Radiat Oncol Biol Phys 2009, 73:685-691.

9. Pinkawa M, Piroth MD, Fischedick K, Nussen S, Klotz J, Holy R, Eble MJ: Self-assessed bowel toxicity after external beam radiotherapy for prostate cancer-predictive factors on irritative symptoms, incontinence and rectal bleeding. Radiat Oncol 2009, 4:36.

10. van Loon J, Grutters J, Macbeth F: Evaluation of novel radiotherapy technologies: what evidence is needed to assess their clinical and cost effectiveness, and how should we get it? Lancet Oncol 2012, 13:e169e177.

11. Deasy JO, Bentzen SM, Jackson A, Ten Haken RK, Yorke ED, Constine LS, Sharma A, Marks LB: Improving normal tissue complication probability models: the need to adopt a "data-pooling" culture. Int J Radiat Oncol Biol Phys 2010, 76:S151-S154.

12. TROG 03.04 RADAR trial - randomised androgen deprivation and radiotherapy. 2005, http://clinicaltrials.gov/ct/show/NCT00193856.

13. Denham JW, Wilcox C, Joseph D, Spry NA, Lamb DS, Tai K-H, Matthews Atkinson C, Turner S, Christie D, Gogna NK, Kenny L, Duchesne G, Delahunt $B$, McElduff P: Quality of life in men with locally advanced prostate cancer treated with leuprorelin and radiotherapy with or without zoledronic acid (TROG 03.04 RADAR): secondary endpoints from a randomised phase 3 factorial trial. Lancet Oncol 2012, 13:1260-1270.

14. Ebert MA, Harrison KM, Howlett SJ, Cornes D, Bulsara M, Hamilton CS, Kron T, Joseph DJ, Denham JW: Dosimetric intercomparison for multicenter clinical trials using a patient-based anatomic pelvic phantom. Med Phys 2011, 38:5167-5175

15. Haworth A, Kearvell R, Greer PB, Hooton B, Denham JW, Lamb D, Duchesne G, Murray J, Joseph D: Assuring high quality treatment delivery in clinical trials - results from the Trans-Tasman Radiation Oncology Group (TROG) study 03.04 "RADAR" set-up accuracy study. Radiother Oncol 2009, 90:299-306.

16. Kearvell R, Haworth A, Ebert MA, Murray J, Hooton B, Richardson S, Joseph DJ, Lamb D, Spry NA, Duchesne G, Denham JW: Quality improvements in prostate radiotherapy: outcomes and impact of comprehensive quality assurance during the TROG 03.04 'RADAR' trial. J Med Imaging Radiat Oncol 2013, 57:247-257.

17. Denham JW, Wilcox C, Lamb DS, Spry NA, Duchesne G, Atkinson C, Matthews J, Turner S, Kenny L, Tai KH, Gogna NK, Ebert M, Delahunt B, McElduff $P$, Joseph D: Rectal and urinary dysfunction in the TROG 03.04 RADAR trial for locally advanced prostate cancer. Radiother Oncol 2012, 105:184-192.

18. International Commission on Radiation Units and Measurements: ICRU Report 62. In Prescribing, Recording, and Reporting Photon Beam Therapy (Supplement to ICRU Report 50). Bethesda, MD: ICRU; 1999.

19. Ebert MA, Haworth A, Kearvell R, Hooton B, Coleman R, Spry N, Bydder S, Joseph D: Detailed review and analysis of complex radiotherapy clinical trial planning data: evaluation and initial experience with the SWAN software system. Radiother Oncol 2008, 86:200-210.

20. Heemsbergen WD, Hoogeman MS, Witte MG, Peeters ST, Incrocci L, Lebesque JV: Increased risk of biochemical and clinical failure for prostate patients with a large rectum at radiotherapy planning: results from the Dutch trial of 68 GY versus 78 Gy. Int J Radiat Oncol Biol Phys 2007, 67:1418-1424.

21. Trotti A, Byhardt R, Stetz J, Gwede C, Corn B, Fu K, Gunderson L, McCormick B, Morrisintegral M, Rich T, Shipley W, Curran W: Common toxicity criteria: version 2.0. an improved reference for grading the acute effects of cancer treatment: impact on radiotherapy. Int I Radiat Oncol Biol Phys 2000, 47:13-47.

22. Lent soma scales for all anatomic sites. Int I Radiat Oncol Biol Phys 1995, 31:1049-1091 (http://www.ncbi.n/m.nih.gov/pubmed/7713776).

23. Christie D, Denham J, Steigler A, Lamb D, Turner S, Mameghan H, Joseph D, Matthews J, Franklin I, Atkinson C, North J, Poulsen M, Spry NA, Tai KH, Wynne C, Duchesne G, Kovacev O, Francis L, Kramar A, D'Este C, Bill D: Delayed rectal and urinary symptomatology in patients treated for prostate cancer by radiotherapy with or without short term neo-adjuvant androgen deprivation. Radiother Oncol 2005, 77:117-125.

24. Schmid MP, Potter R, Bombosch V, Sljivic S, Kirisits C, Dorr W, Goldner G: Late gastrointestinal and urogenital side-effects after radiotherapy-incidence and prevalence. subgroup-analysis within the prospective Austrian-German phase II multicenter trial for localized prostate cancer. Radiother Oncol 2012, 104:114-118.

25. Benjamini Y, Hochberg Y: Controlling the false discovery rate - a practical and powerful approach to multiple testing. J Roy Stat Soc B Met 1995, 57:289-300.

26. R Development Core Team: R: a language and environment for statistical computing. 2013. R Foundation for Statistical Computing, Vienna, Austria. 2013. City: ISBN 3-900051-07-0.

27. Peeters ST, Lebesque JV, Heemsbergen WD, van Putten WL, Slot A, Dielwart MF, Koper PC: Localized volume effects for late rectal and anal toxicity after radiotherapy for prostate cancer. Int I Radiat Oncol Biol Phys 2006, 64:1151-1161

28. Bentzen SM, Dorr W, Gahbauer R, Howell RW, Joiner MC, Jones B, Jones DT, van der Kogel AJ, Wambersie A, Whitmore G: Bioeffect modeling and equieffective dose concepts in radiation oncology-terminology, quantities and units. Radiother Oncol 2012, 105:266-268.

29. Ebert MA FK, Haworth A, Gulliford SL, Kennedy A, Joseph DJ, Denham JW: Gastro-intestinal dose-histogram effects in the context of dose-volume constrained prostate radiotherapy: an analysis of data from the RADAR prostate radiotherapy trial. Int I Radiat Oncol Biol Phys in press 9/11/14

30. Munbodh R, Jackson A, Bauer J, Ross Schmidtlein C, Zelefsky MJ: Dosimetric and anatomic indicators of late rectal toxicity after high-dose intensity modulated radiation therapy for prostate cancer. Med Phys 2008, $35: 2137-2150$

31. Michalski JM, Bae K, Roach M, Markoe AM, Sandler HM, Ryu J, Parliament MB, Straube W, Valicenti RK, Cox JD: Long-term toxicity following 3D conformal radiation therapy for prostate cancer from the RTOG 9406 phase I/I dose escalation study. Int J Radiat Oncol Biol Phys 2010, 76:14-22.

32. Fiorino C, Di Muzio N, Broggi S, Cozzarini C, Maggiulli E, Alongi F, Valdagni R, Fazio F, Calandrino R: Evidence of limited motion of the prostate by carefully emptying the rectum as assessed by daily MVCT image guidance with helical tomotherapy. Int I Radiat Oncol Biol Phys 2008, 71:611-617.

33. Smitsmans MH, Pos FJ, de Bois J, Heemsbergen WD, Sonke JJ, Lebesque JV, van Herk M: The influence of a dietary protocol on cone beam CT-guided radiotherapy for prostate cancer patients. Int I Radiat Oncol Biol Phys 2008, 71:1279-1286.

34. Knoos T, Wieslander E, Cozzi L, Brink C, Fogliata A, Albers D, Nystrom H, Lassen S: Comparison of dose calculation algorithms for treatment planning in external photon beam therapy for clinical situations. Phys Med Biol 2006, 51:5785-5807.

35. Bufacchi A, Nardiello B, Capparella R, Begnozzi L: Clinical implications in the use of the $\mathrm{PBC}$ algorithm versus the AAA by comparison of different NTCP models/parameters. Radiat Oncol 2013, 8:164.

36. McNair HA, Wedlake L, Lips IM, Andreyev J, Van Vulpen M, Dearnaley D: A systematic review: effectiveness of rectal emptying preparation in prostate cancer patients. Pract Radiat Oncol 2014, 4:437-447.

37. Davidson SE, lbbott GS, Prado KL, Dong L, Liao Z, Followill DS: Accuracy of two heterogeneity dose calculation algorithms for IMRT in treatment plans designed using an anthropomorphic thorax phantom. Med Phys 2007, 34:1850-1857.

38. Fowler JF: The radiobiology of prostate cancer including new aspects of fractionated radiotherapy. Acta Oncol 2005, 44:265-276. 
39. Lambin P, Roelofs E, Reymen B, Velazquez ER, Buijsen J, Zegers CM, Carvalho

S, Leijenaar RT, Nalbantov G, Oberije C, Scott Marshall M, Hoebers F, Troost

$E G$, van Stiphout RG, van Elmpt W, van der Weijden T, Boersma L, Valentini $V$, Dekker A: 'Rapid Learning health care in oncology' - an approach towards decision support systems enabling customised radiotherapy. Radiother Oncol 2013, 109:159-164.

doi:10.1186/s13014-014-0282-7

Cite this article as: Yahya et al:: Impact of treatment planning and

delivery factors on gastrointestinal toxicity: an analysis of data from the RADAR prostate radiotherapy trial. Radiation Oncology 2014 9:282.

\section{Submit your next manuscript to BioMed Central and take full advantage of:}

- Convenient online submission

- Thorough peer review

- No space constraints or color figure charges

- Immediate publication on acceptance

- Inclusion in PubMed, CAS, Scopus and Google Scholar

- Research which is freely available for redistribution 